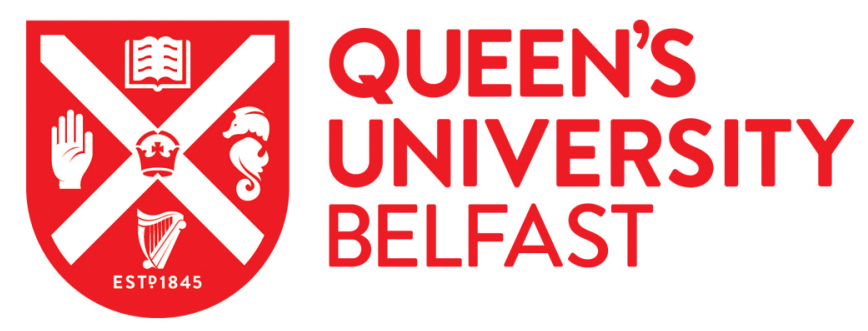

\title{
Implications of between-isolate variation for climate change impact modelling of Haemonchus contortus populations
}

Rose Vineer, H., Steiner, J., Knapp-Lawitzke, F., Bull, K., von Son-de Fernex, E., Bosco, A., Hertzberg, H., Demeler, J., Rinaldi, L., Morrison, A., Skuce, P., Bartley, D., \& Morgan, E. (2016). Implications of betweenisolate variation for climate change impact modelling of Haemonchus contortus populations. Veterinary Parasitology, 229, 144-149. https://doi.org/10.1016/j.vetpar.2016.10.015

Published in:

Veterinary Parasitology

Document Version:

Peer reviewed version

Queen's University Belfast - Research Portal:

Link to publication record in Queen's University Belfast Research Portal

Publisher rights

(C) 2017 Elsevier Ltd.

This manuscript version is made available under the CC-BY-NC-ND 4.0 license http://creativecommons.org/licenses/by-nc-nd/4.0/,which permits distribution and reproduction for noncommercial purposes, provided the author and source are cited

\section{General rights}

Copyright for the publications made accessible via the Queen's University Belfast Research Portal is retained by the author(s) and / or other copyright owners and it is a condition of accessing these publications that users recognise and abide by the legal requirements associated with these rights.

Take down policy

The Research Portal is Queen's institutional repository that provides access to Queen's research output. Every effort has been made to ensure that content in the Research Portal does not infringe any person's rights, or applicable UK laws. If you discover content in the Research Portal that you believe breaches copyright or violates any law, please contact openaccess@qub.ac.uk. 
1 Implications of phenotypic trait variation for climate change impact modelling of

\section{Haemonchus contortus populations}

3 Rose, H. $^{1,2,3}$, Steiner, J. ${ }^{4}$, Knapp-Lawitzke, F. ${ }^{5}$, Bull, K. ${ }^{2}$, von Son-de Fernex, E. ${ }^{5}$, Bosco, A. ${ }^{7}$, Hertzberg,

$4 \quad \mathrm{H}^{4}{ }^{4}$, Demeler, J. ${ }^{5}$, Rinaldi, L. ${ }^{7}$, Morrison, A. ${ }^{8}$, Skuce, P. ${ }^{8}$, Bartley, D. ${ }^{8}$, Morgan, E. R ${ }^{2,3}$.

$5 \quad{ }^{1}$ School of Biological Sciences, University of Bristol, 24 Tyndall Avenue, Bristol, UK, BS8 1TQ

$6 \quad{ }^{2}$ School of Veterinary Sciences, University of Bristol, Langford House, Bristol, UK, BS40 5DU

$7 \quad{ }^{3}$ Cabot Institute, University of Bristol, Cantocks Close, Bristol, UK, BS8 1TS

$8{ }^{4}$ Institut für Parasitologie, University of Zurich, Winterthurerstrasse 266a, CH-8057, Zürich

9 Institut für Parasitologie und Tropenveterinärmedizin, Freie Universität Berlin, Robert-von-Ostertag-

10 Str. 7-13,14163 Berlin

$11{ }^{6}$ Centro de Enseñanza Investigación y Extensión en Ganadería Tropical, Facultad de Medicina

12 Veterinaria y Zootecnia, Universidad Nacional Autónoma de México, Km 5.5 Carretera Federal

13 Tlapacoyan-Martínez de la Torre, C.P. 93600, Veracruz, México

$14{ }^{7}$ Department of Veterinary Medicine and Animal Productions, University of Naples Federico II,

15 CREMOPAR Regione Campania, Naples, Italy

$16{ }^{8}$ Moredun Research Institute, Pentlands Science Park, Bush Loan, Penicuik, Scotland EH26 OPZ

17 Corresponding author: hannah.rose@bristol.ac.uk +44(0) 1173941383 
21 The impact of climate change on parasites and parasitic diseases is a growing concern and numerous empirical and mechanistic models have been developed to predict climate-driven spatial and temporal changes in the distribution of parasites and disease risk. Geographical variation in parasite phenotype could undermine the application of such models at broad spatial scales. Seasonal variation in the transmission of the haematophagous gastrointestinal nematode Haemonchus contortus, one of the most pathogenic helminth species infecting sheep and goats worldwide, is

27 primarily determined by the impact of environmental conditions on the free-living stages. To evaluate variability in the development success and mortality of the free-living stages of $H$. contortus and the impact of this variability on future climate impact modelling, three isolates of diverse geographical origin were cultured at a range of temperatures between $15^{\circ} \mathrm{C}$ and $37^{\circ} \mathrm{C}$ to determine their development success compared with simulations using the GLOWORM-FL H. contortus model. No significant difference was observed in the developmental success of the three isolates of $H$. contortus tested, nor between isolates and model simulations. However, development success of all isolates at $37^{\circ} \mathrm{C}$ was lower than predicted by the model, suggesting the potential for overestimation of transmission risk at higher temperatures, such as those predicted under some scenarios of climate change. Recommendations are made for future climate impact modelling of gastrointestinal nematodes. 
The impact of climate change on the distribution of parasites and parasitic diseases is a growing concern and empirical and mechanistic models have been developed to predict climate-driven spatial and temporal changes in the distribution of parasites and disease risk (Wall and Ellse, 2011; Rose et al., accepted; Caminade et al., 2015). These models are often employed to make predictions on broad spatial and temporal scales, under the assumption that the underlying determinants of parasite ecology are conserved in time and space.

Gastrointestinal nematodes (GINs) infecting ruminants affect host productivity and welfare worldwide (Nieuwhof and Bishop 2005; Charlier et al., 2014) and numerous models aiming to optimise control strategies have been developed (reviewed by Cornell, 2005). In recent years, attention has shifted to the impacts of climate change on GINs and models have been developed that are largely parameterised using data on the average response of parasites to environmental stochasticity (Molnár et al., 2013; Rose et al., 2015). However GINs are genetically diverse within species (Troell et al., 2006a; Hunt et al., 2008; Redman et al., 2008). Phenotypic diversity is also observed but varies by trait (LeJambre and Whitlock, 1976; Troell et al., 2006b; Hunt et al., 2008; Angulo-Cubillán et al., 2010; van Dijk and Morgan, 2010). Regional differences in parasite phenology arising from this variation may undermine modelling efforts if the level of variation is sufficient to result in biologically meaningful disparities between model predictions and parasite behaviour. Seasonal variation in the transmission of the haematophagous GIN Haemonchus contortus, one of the most pathogenic GIN species infecting sheep and goats worldwide, is primarily determined by the impact of environmental conditions on the free-living stages. The objectives of this study were therefore to evaluate variability in the development success and mortality of the free-living stages of H. contortus isolates at a range of temperatures and assess the impact of this variability on the output of a model developed to simulate the climate-dependent population dynamics of $H$. contortus. 
Three pure isolates of $H$. contortus were used; $\mathrm{MHcO}$ (ISE) provided by the Moredun Research Institute, $\mathrm{HC} 1 \mathrm{CH}$ provided by the University of Zurich, and the McMaster isolate provided by the Freie Universität Berlin. All isolates were susceptible to anthelmintics. MHco3(ISE) was derived from the ISE H. contortus isolate, which itself is derived from the SE isolate, thought to have originated from East Africa (Kenya) in the 1950s (Redman et al., 2008; Sargison, 2008). The McMaster isolate has a similar history of laboratory maintenance, having been isolated from sheep in Australia in 1931 (Hunt et al., 2008). The $\mathrm{HC1CH}$ isolate was purified from naturally infected sheep in the Swiss midland region for in vitro anthelmintic resistance tests, and has been maintained under laboratory conditions at the University of Zurich since 2002.

\subsection{Collection and transport of faeces containing H. contortus eggs}

Faeces containing eggs were collected from donor lambs (infected for reasons other than the present study) using a harness over a 4-24 hour period. Faeces containing eggs of the $\mathrm{HC} 1 \mathrm{CH}$ isolate were vacuum packed for preservation (Rinaldi et al., 2015), transported to the University of Bristol by passenger airline and used within 12 hours of arrival (total transit time $<48$ hours). Faeces containing eggs of the MHco3(ISE) isolate were also vacuum packed, posted by Royal Mail to the University of Bristol and used immediately upon arrival (total transit time $<24$ hours). Experiments using the McMaster isolate were conducted at Freie Universität Berlin and therefore faeces were used within 8 hours of collection.

\subsection{Experiment design}

Faeces were mixed thoroughly and a minimum of 3 egg counts conducted using the modified McMaster's method, sensitive to 50 eggs per gram (epg; MAFF, 1986). At the same time, the developmental stage of $\mathrm{HC} 1 \mathrm{CH}$ and $\mathrm{MHco3}$ (ISE) eggs was recorded as unembryonated (up to late 
gastrula stage) or embryonated ("comma" stage onwards) to ensure only undeveloped eggs were used.

91 Subsamples of the homogenised faeces weighing $3 \mathrm{~g}$ each were placed in $6 \mathrm{~cm}$ diameter petri dishes and incubated at $15^{\circ} \mathrm{C}, 25^{\circ} \mathrm{C}$ or $37^{\circ} \mathrm{C}$ for 23,12 or 5 days respectively. The temperatures were chosen to capture peak of $H$. contortus $\mathrm{L} 3$ recovery at $20-25^{\circ} \mathrm{C}$ and to span the range of maximum summer temperatures experienced throughout the majority of Europe under current conditions (Klein Tank et al., 2002). The upper temperature of $37^{\circ} \mathrm{C}$ was included to capture extreme high temperatures that may be experienced in the dung due to solar radiation (Hertzberg, $\mathrm{H}_{\text {., }}$ unpublished data) and predicted future increases in climate extremes (Kovats et al., 2014). Incubation times were derived from time to peak L3 recovery at each temperature, estimated using the GLOWORM-FL model of the population dynamics of $H$. contortus (Figure 1; Rose et al., 2015). A minimum of 5 replicates per temperature, per isolate, were used.

Cultures were kept moist throughout experiments by the addition of tap water when condensation no longer formed on the petri dish lid or if faeces appeared to be drying. One MHco3(ISE) replicate was lost at $15^{\circ} \mathrm{C}$ due to overgrowth of fungal hyphae. L3 were harvested after the respective incubation period using a modified Baermann's method (MAFF, 1986), and the percentage of eggs that yielded L3 was estimated.

Observations on the McMaster isolate were extended to 12 and 23 days to estimate mortality rates at temperatures beyond those typically observed in the field $\left(37^{\circ} \mathrm{C}\right.$ only) and to examine changes in the proportion of $L 3$ exsheathed over time.

\subsection{Statistical analysis}

110 The percentage yield was compared between isolates using a Two-way ANOVA in R (R Core Team,

111 2015). Plots of the residuals were checked for significant departures from normality,

112 heteroscedasticity and influential data points. The expected development success was simulated for 

correlation was used to compare model predictions with observed L3 yield for all isolates combined.

115 The mortality rate of $\mathrm{L} 3$ at $37^{\circ} \mathrm{C}$ was estimated for the McMaster isolate using the proportion

116 surviving the 18 day period between 5 and 23 days incubation: - $\ln ($ proportion surviving)/18. The

117 decrease in numbers of $\mathrm{L} 3$ in faeces over time at $37^{\circ} \mathrm{C}$ was then simulated using the GLOWORM-FL

118 model and either the mortality rate estimated in this study and the mortality rate defined by Rose et

119 al. (2015) to examine the impact of variability in mortality rates between isolates on numbers of L3. 


\section{Results}

122 Mean egg counts (S.D.) on day 0 were 8374 epg (119.6; MHco3(ISE)), 934 epg (125.8; HC1CH), and 6358 epg (1253.6; McMaster). All eggs were unembryonated at the time of egg counting.

124 The number of larvae recovered was significantly greater than the egg counts obtained by modified

125 McMaster's technique. Egg counts were therefore corrected based on a recovery efficiency of $40 \%$

126 (Table 1; Morgan, E. R. unpublished data). There was no significant difference in L3 yield (Figure 2)

127 between isolates $\left(F_{2,58}=0.645, \mathrm{MSE}=537, \mathrm{p}=0.528\right)$ and there was no interaction between isolates

128 and temperature $\left(F_{2,58}=0.636, \mathrm{MSE}=529, \mathrm{p}=0.533\right)$.

129 There were apparent departures in observed L3 yield from simulated L3 yield (Figure 2). Observed L3

130 yield was lower than simulated for all three isolates at $37^{\circ} \mathrm{C}$, and a higher $\mathrm{L} 3$ yield than simulated

131 was observed for the $\mathrm{HC} 1 \mathrm{CH}$ at $25^{\circ} \mathrm{C}$. However, observed and simulated $\mathrm{L} 3$ yield were positively

132 correlated (Spearman's $\rho=0.66, \mathrm{~S}=14992.44, \mathrm{p}<0.001$ ).

133 Mortality of the McMaster isolate was rapid at $37^{\circ} \mathrm{C}$ and a mean of $75 \%$ of $\mathrm{L} 3$ recovered on day 23

134 were exsheathed (Table 2). Based on these data, an instantaneous daily mortality rate over days 5-

13523 of 0.252 was estimated, compared with 0.197 estimated by Rose et al. (2015). Nevertheless,

136 simulations using both mortality rates yielded similar results (Figure 3). 
No significant difference was observed in the developmental success of the three isolates of $H$. contortus tested in this study, despite their disparate origins (East Africa, Australia and Switzerland) and the potential for high levels of genetic differentiation between isolates (Redman et al., 2008). However, the numbers of $L 3$ recovered from cultures maintained at $37^{\circ} \mathrm{C}$ appeared to be lower than predicted by the model, suggesting the potential for overestimation of transmission risk at higher temperatures. This is unlikely to be an artefact of the correction for egg recovery during faecal egg counting as this would affect all temperatures equally, resulting in a systematic overestimation by the model and not an overestimate at a single temperature. When simulations using the L3 mortality rates estimated from observations on the McMaster isolate were compared with simulations using the L3 mortality rates defined by Rose et al. (2015), there was little biologically meaningful impact on the predicted numbers of $L 3$ over time, suggesting that the reduced recovery rate of $L 3$ from faeces incubated at $37^{\circ} \mathrm{C}$ compared with the numbers expected from simulations may be due to an increase in the mortality of eggs and/or pre-infective larvae. This is unlikely to affect model simulations using current temperate climatic conditions and no significant difference was found between isolates and the GLOWORM-FL model simulations in this study. However, when the model is applied to scenarios where extreme high temperatures are predicted e.g. some future climate projections or in equatorial regions, the cumulative impact of these small variations may be significant, and additional model validation may be required.

The GLOWORM-FL model was parameterised using data from a number of sources where possible to capture variation between isolates (Rose et al., 2015). However, mortality rates of eggs and preinfective larvae in the GLOWORM-FL H. contortus model were based on relatively few data points. Further data were unavailable, presumably due to the difficulties inherent in disentangling the confounding effects of development to the next life cycle stage and mortality. As a result, only 
the rate of increase in mortality rates with extreme high temperatures might be underestimated.

The results presented here may justify modification of the egg and pre-infective larvae mortality parameters in the GLOWORM-FL H. contortus model if this is supported by field validation of the updated model.

Troell et al. (2006b) observed a similar response to cold treatment in $H$. contortus L3 from Kenya and

Sweden (no significant differences between arrest rates, establishment rates nor pre-patent periods). The authors concluded that "there was limited evidence for adaptations to temperate climatic conditions". However, under untreated conditions (fresh L3) significantly higher arrest rates and longer pre-patent periods were observed in the Swedish isolate, which would act to stabilise populations in the absence of free-living stages (Gaba and Gourbière, 2008), as is common during the Swedish winter, and one could argue that this is evidence of local adaptation. Therefore, the potential for the degree of local adaptation to vary from trait to trait should be addressed when extrapolating knowledge and models to different regions, for example by conducting additional validation to ensure the response of local populations of parasites is captured by model predictions. Moreover, differences have been observed in the temperature thresholds and rates of egg hatching from H. contortus of different geographical origin (Crofton and Whitlock, 1965; Crofton et al, 1965). More comprehensive data on parasite responses across a broader temperature range would be useful, but are difficult to obtain, especially from field populations, which are usually of mixed species composition.

Finally, changes in selection pressures under future climate change scenarios and adaptation and evolution of parasite populations in response to these changes is difficult to incorporate into climate impact simulations and as a result most models make assumptions of no adaptation (Rose et al., 2015; Caminade et al., 2015). However, such assumptions may be quickly invalidated. For example, regional variation in the hatching behaviour of the GIN Nematodirus battus has been observed in the 
to explore trait variation in GINs and identify traits which may be subject to altered selection pressure under climate change scenarios.

The $H$. contortus isolates used in this study were all laboratory isolates which may have adapted to laboratory conditions. Of particular relevance to this study is the reduced pressure to achieve efficient transmission that these isolates experience during routine passage, which typically involves culture of faeces containing eggs from donor animals and oral administration of $\mathrm{L} 3$ to recipient animals. Furthermore, the relatively constant conditions experienced by these isolates in the laboratory environment may have led to loss of adaptations to local climates. Under these circumstances, the loss of 'expensive' adaptive traits determining L3 fitness such as migration ability (Knapp-Lawitzke et al., submitted) may be seen, and there may be a regression to a mean phenotype that is well adapted to laboratory environments. Additional work on field isolates to further explore the potential impact of phenotypic trait variation could therefore be valuable. However, purified field isolates are both expensive and difficult to obtain, particularly if the aim is to minimise selection pressure (i.e. minimise the number of passages). This may preclude observations on a range of isolates as presented here. Furthermore, significant genetic differentiation has been detected between laboratory isolates from different geographic origins (Redman et al., 2008). Therefore laboratory isolates are a valuable and valid alternative to field isolates.

Based on the observations in the present study and previous observations of phenotypic variation in GIN populations (e.g. Troell et al., 2006b), the following recommendations should be implemented where possible, to increase confidence in climate impact modelling of GINs: parameters should be derived from data from multiple field and laboratory isolates to capture variation; models should be validated using field data from several regions with a range of climatic conditions encompassing both extreme high and low temperatures and rainfall to identify areas of uncertainty in the parameter space; parameters should be calibrated to locally adapted populations if data are 
213 for future adaptation should be considered and assumptions of no adaptation made clear when

214 reporting model output.

215

216 Acknowledgements

217 The work was supported by funding from the FP7 GLOWORM project - Grant agreement $\mathrm{N}^{\circ}$

218 288975CP-TP-KBBE.2011.1.3-04 (www.gloworm.eu). We thank Dr Brian Boag for useful discussions. 
Angulo-Cubillán, F. J., García-Coiradas, L., Alunda, J. M., Cuquerella, M., de la Fuente, C., 2010.

Biological characterization and pathogenicity of three Haemonchus contortus isolates in primary infections in lambs. Vet. Parasitol. 171, 99-105.

Caminade, C., van Dijk, J., Baylis, M., Williams, D., 2015. Modelling recent and future climatic suitability for fasciolosis in Europe. Geospat. Health 9, 301-308.

Charlier, J., van der Voort, M., Kenyon, F., Skuce, P., Vercruysse, J., 2014. Chasing helminths and their economic impact on farmed ruminants. Trends Parasitol. 30, 361-367.

Cornell, S., 2005. Modelling nematode populations: 20 years of progress. Trends Parasitol. 21, 542545.

Crofton, H.D., Whitlock, J.H., 1965. Ecology and biological plasticity of sheep nematodes. 4. Biological significance of temperature to time hatching curves for eggs of sheep nematodes. Cornell Vet. 55, 263-274.

Crofton, H.D., Whitlock, J.H., Glazer, R.A., 1965. Ecology and biological plasticity of sheep nematodes. 2. Genetic to environmental plasticity in Haemonchus contortus (Rud 1802). Cornell Vet. $55,263-274$.

Gaba, S., Gourbière, S., 2008. To delay once or twice: the effect of hypobiosis and free-living stages on the stability of host-parasite interactions. J. R. Soc. Interface. 5, 919-928. differences between isolates of Haemonchus contortus in Australia. Int. J. Parasitol. 38, 885-900. Pashiardis, S., Hejkrlik, L., Kern-Hansen, C., Heino, R., Bessemoulin, P., Müller-Westermeier, G., 
Bukantis, A., Aberfeld, R., van Engelen, A. F. V., Forland, E., Mietus, M., Coelho, F., Mares, C.,

Razuvaev, V., Nieplova, E., Cegnar, T., Antonio López, J., Dahlström, B., Moberg, A., Kirchhofer, W.,

Ceylan, A., Pachaliuk, O., Alexander, L. V., Petrovic, P., 2002. Daily dataset of 20th-century surface air temperature and precipitation series for the European Climate Assessment. Int. J. Climatol. 22, 1441-1453.

Kovats, R. S., Valentini, R., Bouwer, L. M., Georgopoulou, E., Jacob, D., Martin, E., Rounsevell, M., Soussana, J.-F., 2014. Europe. In: Climate Change 2014: Impacts, Adaptation, and Vulnerability. Part B: Regional Aspects. Contribution of Working Group II to the Fifth Assessment Report of the Intergovernmental Panel on Climate Change [Barros, V.R., Field, C. B., Dokken, D. J., Mastrandrea, M. D., Mach, K. J., Bilir, T. E., Chatterjee, M., Ebi, K. L., Estrada, Y. O., Genova, R. C., Girma, B., Kissel, E. S., Levy, A. N., MacCracken, S., Mastrandrea, P. R., White, L. L. (eds.)]. Cambridge University Press, Cambridge, United Kingdom and New York, NY, USA, pp. 1267-1326. between geographic regions. Parasitol. 73, 223-238. MAFF, 1986. Manual of Veterinary Parasitological Laboratory Techniques HMSO. MAFF, London.

Molnár, P. K., Kutz, S. J., Hoar, B. M., Dobson, A. P., 2013. Metabolic approaches to understanding climate change impacts on seasonal host-macroparasite dynamics. Ecol. Lett. 16, 9-21. and the potential benefits of reduction in disease impact. Anim. Sci. 81, 23-29.

R Core Team, 2015. R: A language and environment for statistical computing. R Foundation for Statistical Computing, Vienna, Austria. reveals marked genetic differentiation between Haemonchus contortus laboratory isolates and provides a rapid system of genetic fingerprinting. Int. J. Parasitol. 38, 111-122. 

distribution for infection in sheep in Europe. Geospat. Health 9, 325-331.

Rose, H., Caminade, C., Bolajoko,M. B., Phelan, P., van Dijk, J., Baylis, M., Williams, D., Morgan, E. R., Accepted. Climate-driven changes to the spatio-temporal distribution of the parasitic nematode, Haemonchus contortus, in sheep in Europe. Glob. Change. Biol.

Rose, H., Wang, T., van Dijk, J., Morgan, E. R., 2015. GLOWORM-FL: A simulation model of the effects of climate and climate change on the free-living stages of gastro-intestinal nematode parasites of ruminants. Ecol. Modell. 297, 232-245.

Sargison, N. D., 2008. Development of genetic crossing methods to identify genes associated with macrocyclic lactone resistance in the sheep nematode parasite, Haemonchus contortus. PhD thesis, University of Edinburgh, UK.

Troell, K., Engström, A., Morrison, D. A., Mattsson, J. G., Höglund, J., 2006a. Global patterns reveal strong population structure in Haemonchus contortus, a nematode parasite of domesticated ruminants. Int. J. Parasitol. 38, 1305-1316. study of isolates from Sweden and Kenya in experimentally infected sheep. Parasitol. 132, 403-409. Polymorphic bet hedging? Int. J. Parasitol. 40, 675-681. blowfly strike in a warmer environment. Glob. Change Biol. 17, 1770 - 1777. 
Figure 1. Simulated maximum percentage L3 yield (solid line) and time to maximum L3 yield (dashed line) at constant temperatures between $0^{\circ} \mathrm{C}$ and $40^{\circ} \mathrm{C}$.

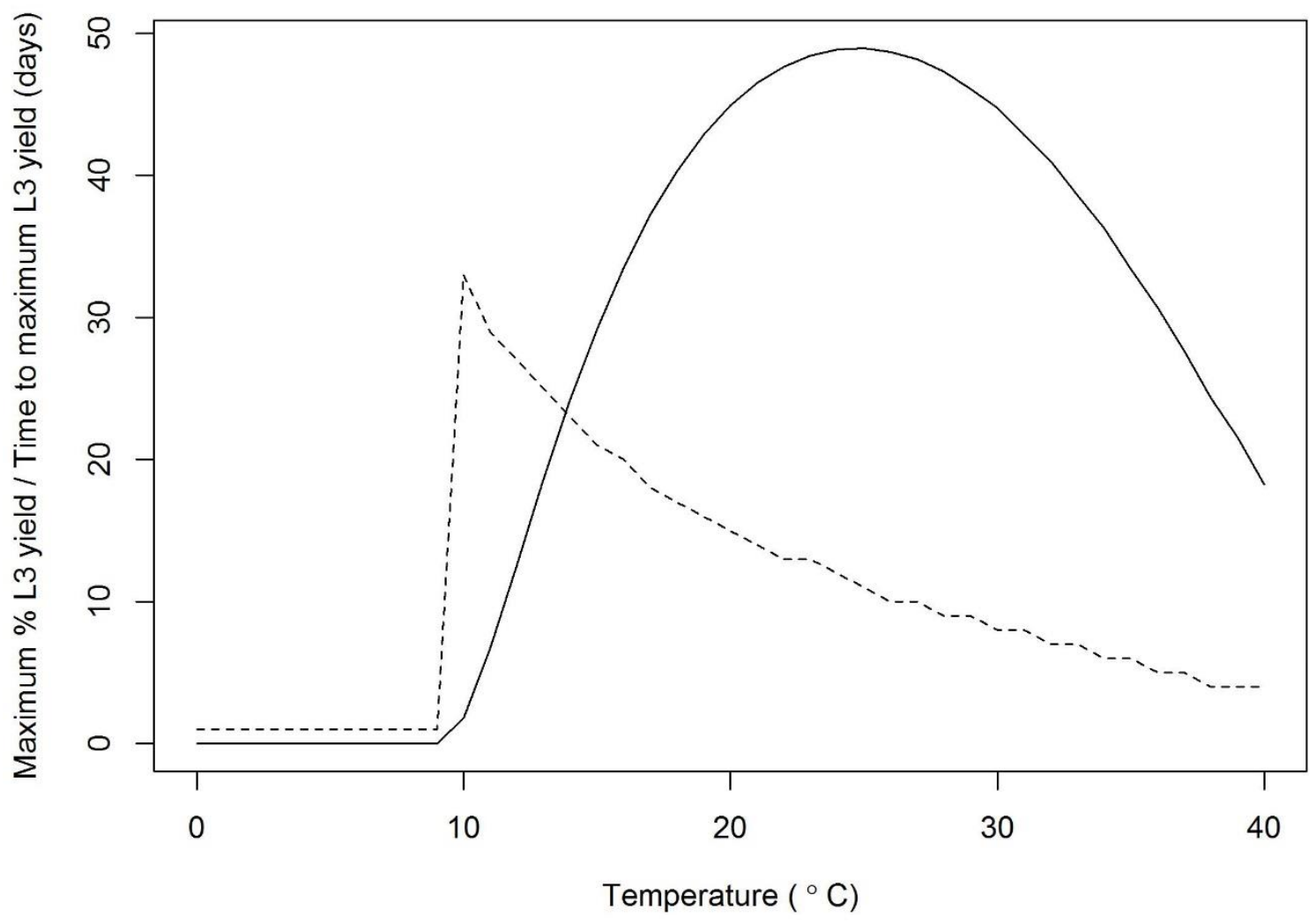

289 
Figure 2. Mean percentage L3 yield (points) and $95 \%$ confidence intervals (whiskers) for $\mathrm{H}$. contortus isolates tested at $15^{\circ} \mathrm{C}, 25^{\circ} \mathrm{C}$ and $37^{\circ} \mathrm{C}$ (points offset for

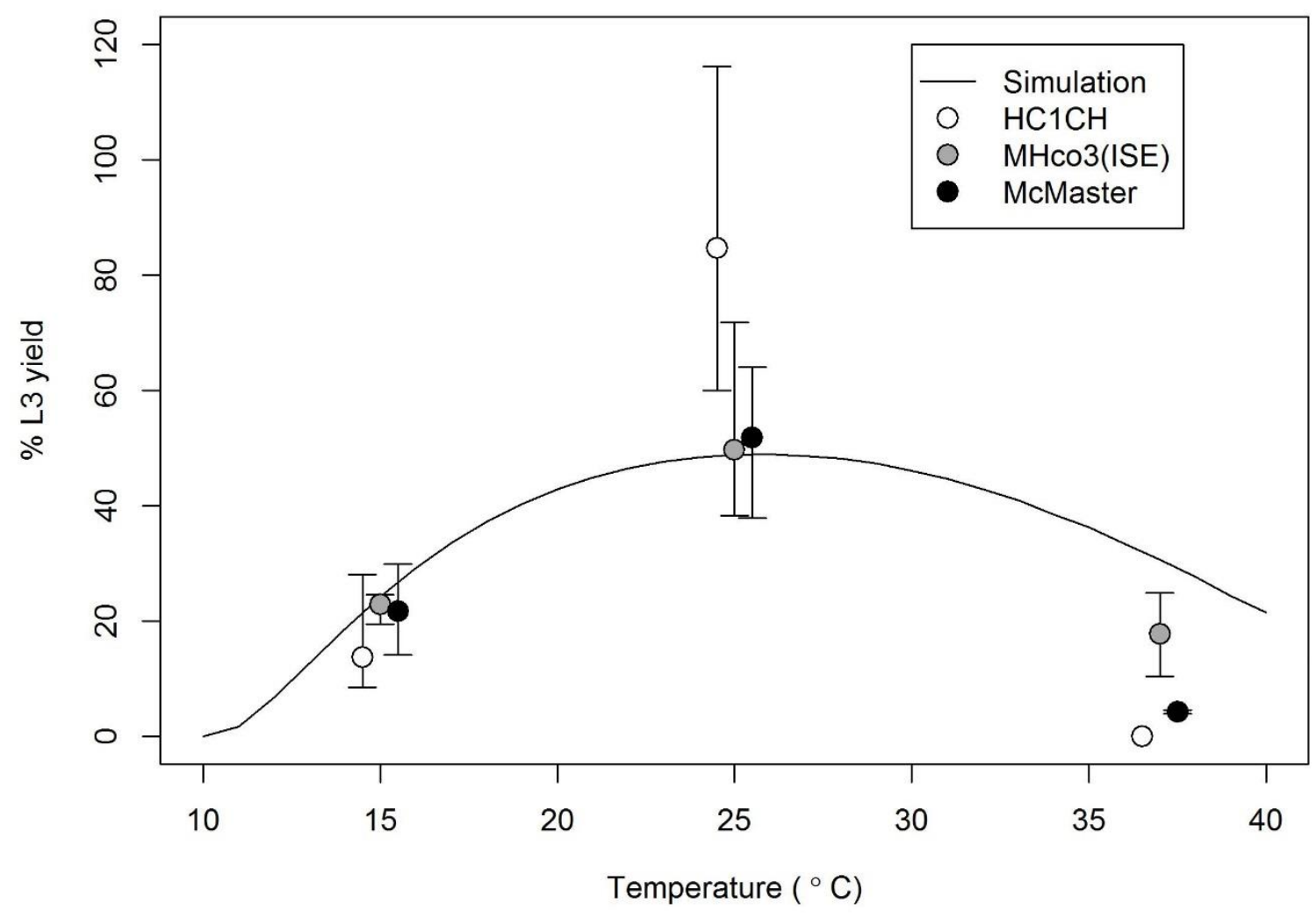



numbers of McMaster L3 surviving (solid line; Table S2), with the observed numbers of L3 superimposed.

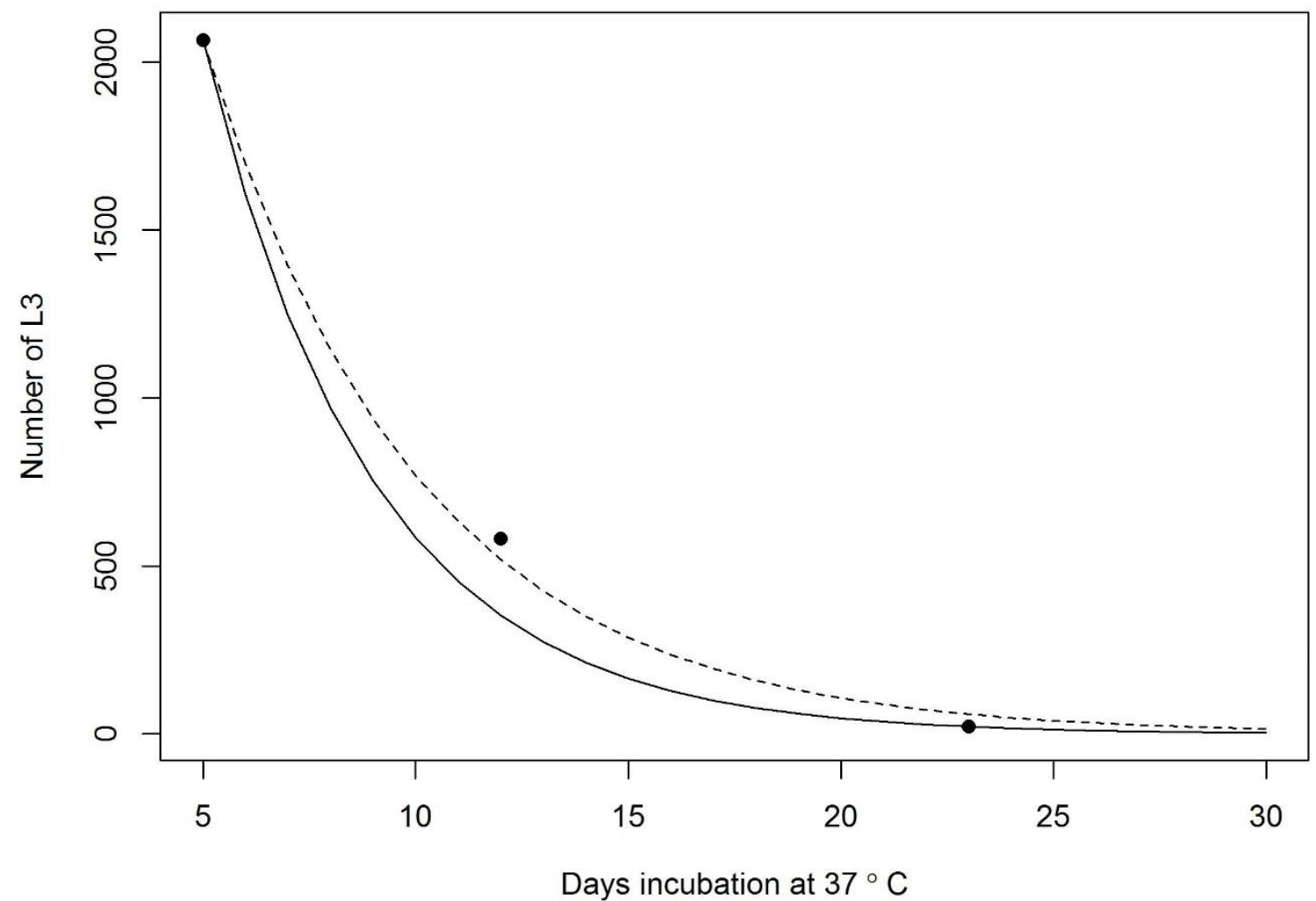


Table 1. Observations of L3 yield in three $H$. contortus isolates and predicted L3 yield based on the GLOWORM-FL $H$. contortus model (Rose et al., 2015). Egg counts corrected for a $40 \%$ recovery efficiency were used to estimate percentage $\mathrm{L} 3$ yield.

\begin{tabular}{|c|c|c|c|c|c|c|c|c|c|c|c|}
\hline Isolate / data & EPG (S.D.) & Corrected EPG & & & & & L3 yield & & & & \\
\hline \multirow[t]{2}{*}{ source } & & \multirow[t]{2}{*}{ (S.D.) } & \multicolumn{3}{|c|}{$15^{\circ} \mathrm{C}$} & \multicolumn{3}{|c|}{$25^{\circ} \mathrm{C}$} & \multicolumn{3}{|c|}{$37^{\circ} \mathrm{C}$} \\
\hline & & & $\mathbf{n}$ & LPG (S.D.) & $\%$ & $\mathbf{n}$ & LPG (S.D) & $\%$ & $\mathrm{n}$ & LPG (S.D) & $\%$ \\
\hline MHco3(ISE) & 8374 (199.6) & 20935 (499.1) & 4 & 4791.7 (523.6) & $22.9(2.5)$ & 10 & $10400(2311.3)$ & $49.7(11)$ & 10 & $3715.8(1012.3)$ & $17.7(4.8)$ \\
\hline $\mathrm{HC1CH}$ & $934(125.8)$ & 2335 (314.5) & 5 & $320(214.2)$ & $13.7(9.1)$ & 10 & $1977.5(478.8)$ & $84.7(20.5)$ & 10 & $0(0)$ & $0(0)$ \\
\hline McMaster & $6358.3(1253.6)$ & 15895.8 (3133.9) & 5 & $3451.1(1058.2)$ & $21.7(6.7)$ & 5 & 8234 (1685.5) & $51.8(10.6)$ & 5 & $688.7(50.5)$ & $4.3(0.3)$ \\
\hline GLOWORM- & - & - & 1 & - & 24 & 1 & - & 49 & 1 & - & 30 \\
\hline FL model & & & & & & & & & & & \\
\hline
\end{tabular}


Table 2. Numbers of $H$. contortus McMaster isolate $L 3$ recovered at intervals from $3 g$ faeces incubated at $37^{\circ} \mathrm{C}$, and the percentage of exsheathed $\mathrm{L} 3$.

\begin{tabular}{|c|c|c|c|c|c|c|c|c|c|}
\hline & \multicolumn{3}{|c|}{5 days } & \multicolumn{3}{|c|}{12 days } & \multicolumn{3}{|c|}{23 days } \\
\hline & Total L3 & Exsheathed & $\%$ exsheathed & Total L3 & Exsheathed & $\%$ exsheathed & Total L3 & Exsheathed L3 & $\%$ exsheathed \\
\hline & & L3 & & & L3 & & & & \\
\hline Replicate 1 & 2170 & 0 & 0 & 270 & 94 & 34.78 & 0 & NA & NA \\
\hline Replicate 2 & 2150 & 0 & 0 & 210 & 77 & 36.84 & 0 & NA & NA \\
\hline Replicate 3 & 2200 & 0 & 0 & 150 & 30 & 20.00 & 80 & 40 & 50 \\
\hline Replicate 4 & 1950 & 0 & 0 & 100 & 24 & 23.81 & 20 & 20 & 100 \\
\hline Replicate 5 & 1860 & 0 & 0 & 2180 & 569 & 26.09 & 10 & NA & NA \\
\hline Mean & 2066.00 & 0 & 0 & 582.00 & 158.80 & 28.30 & 22.00 & 30.00 & 75.00 \\
\hline S.D. & 151.43 & 0 & 0 & 895.58 & 231.25 & 7.23 & 33.47 & 14.14 & 35.36 \\
\hline
\end{tabular}

